\title{
What Has Computed Tomography Taught Us about the Acute Respiratory Distress Syndrome?
}

\author{
LUCIANO GATTINONI, PIETRO CAIRONI, PAOLO PELOSI, and LAWRENCE R. GOODMAN
}

Istituto di Anestesia e Rianimazione, Università degli Studi di Milano, Ospedale Maggiore Policlinico—IRCCS, Milano, Italy; and Department of Radiology, Medical College of Wisconsin, Milwaukee, Wisconsin

\section{CONTENTS}

Introduction

Morphological Analysis of the CT Images

Early Phase [First Week]

Late Stage [Second Week and Beyond]

Long-Term Follow-up

Pathogenesis Alters Morphology

Quantitative Analysis of CT Scan Images

CT Frequency Distribution

Lung Compartments

CT Scan Protocols and Analysis Influence Results

One to Three Slices versus Whole Lung CT Scan

Recruitment

Hyperinflation and Overstretching

Structure-Function Correlation in the Whole Lung

Gas Exchange

Lung Mechanics

CT-Regional Analysis

Edema Distribution and Lung Volume

Superimposed Pressure and PEEP

The CT Scan and Mechanical Ventilation Settings

Opening the Lung

Interaction between End Expiration and End Inspiration

Distribution of Gas in Mechanical Ventilation

Intratidal Collapse and Decollapse

The Impact of CT Scanning in Clinical Practice

New Developments and Future Areas of Research

Although computed body tomography (CT) first became available in the mid-1970s, the first reports of CT imaging of acute respiratory failure (currently classified as acute lung injury [ALI] or acute respiratory distress syndrome [ARDS]) did not appear until almost a decade later (1-3). Why did it take so long to apply CT scanning to human ALI/ARDS? Early CT scanners were slow (8-18 s/axial image), CT scanners were few and often overbooked, and transport of the critically ill was considered difficult. More importantly, ARDS was believed to affect both lungs homogeneously and CT scanning, under such circumstances, was not considered beneficial. The impetus to study ALI/ARDS patients with CT followed the pioneering CT studies by Brismar and coworkers of normal subjects during anesthesia and paralysis (4). They consistently found, in normal anesthetized men, in-

(Received in original form March 27, 2001; accepted in final form August 13, 2001)

Correspondence and requests for reprints should be addressed to Prof. Luciano Gattinoni, Istituto di Anestesia e Rianimazione, Università degli Studi di Milano, Ospedale Maggiore di Milano-IRCCS, Via Francesco Sforza 35, 20122 Milano, Italy. E-mail: gattinon@polic.cilea.it

Am J Respir Crit Care Med Vol 164. pp 1701-1711, 2001

DOI: $10.1164 / \mathrm{rccm} 2103121$

Internet address: www.atsjournals.org creased CT lung density in the gravity-dependent lung regions. This increased lung density was felt to be due to the loss of muscle tone caused by anesthesia, and was termed "compression atelectasis." Because many ALI/ARDS patients are also sedated and/or paralyzed, we postulated that "compression atelectasis" may be present to a greater or lesser degree in patients with respiratory insufficiency. The early CT papers of ALI/ARDS showed the lung disease in ALI/ARDS to be more heterogeneous than initially believed (Figure 1). CT dramatically and permanently changed the understanding of this syndrome $(2,3)$. The CT scan, over the years, has proven to be an exceptional tool in understanding the physiopathology of ALI/ARDS, and it is now increasingly used in clinical practice as well.

In this report, we will review how CT scanning has increased our understanding of the physiopathology and clinical management of ALI/ARDS.

\section{MORPHOLOGICAL ANALYSIS OF THE CT IMAGES}

Over the past 15 years, many reports, both experimental and clinical, have described the different CT morphological patterns found in ALI/ARDS. Unfortunately, most of the series were limited in size, used different methodological approaches and different generations of $\mathrm{CT}$ equipment, and varied greatly in terminology for describing morphological changes. However, despite these differences, the CT findings taken together definitively refute the commonly held belief, based on chest radiography, that ALI/ARDS is a homogeneous parenchymal process. Indeed, the CT scan has conclusively shown that ALI/ ARDS is an inhomogeneous process, ALI/ARDS morphology varies with etiology, and ALI/ARDS morphology changes with time, mechanical ventilation, and patient position.

Since anatomic descriptors have varied so greatly, it is worthwhile to precisely define the CT terminology. We have adopted the descriptors proposed by the Fleischner Society Nomenclature Committee (5).

Accordingly:

1. ground-glass opacification: a hazy increase in lung attenuation, with preservation of bronchial and vascular margins;

2. consolidation: a homogeneous increase in lung attenuation that obscures bronchovascular margins in which an airbronchogram may be present;

3. reticular pattern: innumerable interlacing line shadows that may be fine, intermediate, or coarse.

These morphological alterations were all found in CT scans of ALI/ARDS patients. Although the pathophysiological meaning of the morphological patterns described above is likely to be different for different lung diseases, in ALI/ARDS the ground glass opacification is thought to reflect an active inflammatory process involving both the lung interstitium, with abnormal thickening of the alveolar wall, and incomplete filling of the al- 


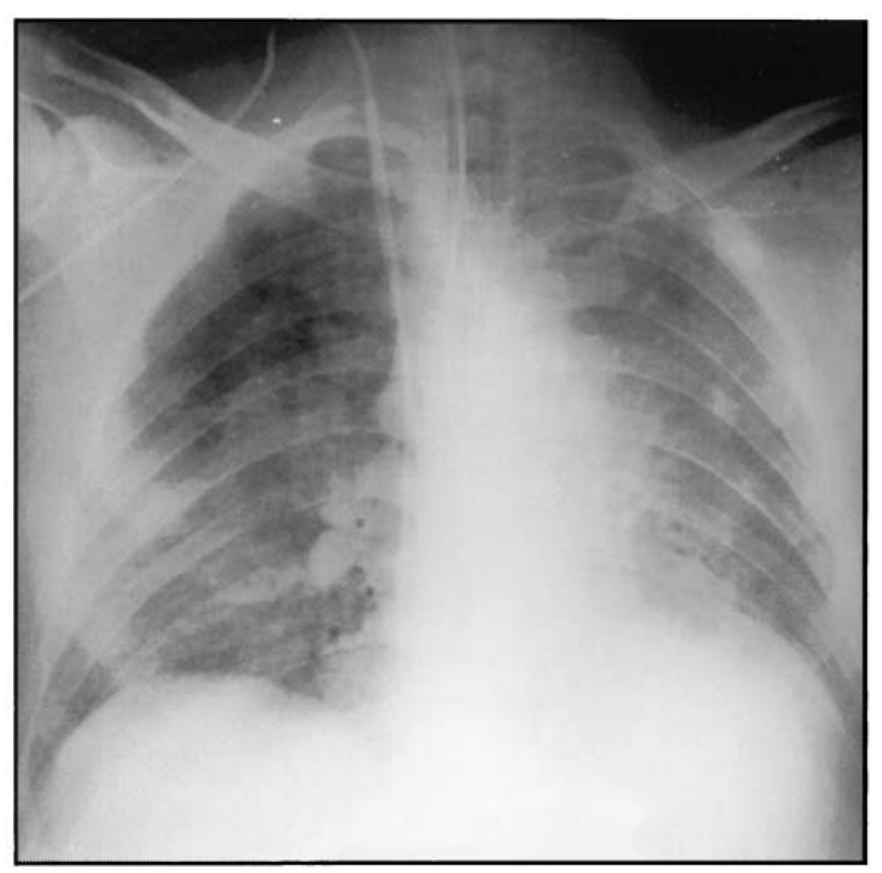

veolar space with inflammatory cells, cellular debris, and edema (6). Consolidation, otherwise referred to as dense parenchymal opacification, whether patchy or diffuse, usually refers to pulmonary parenchyma, which is completely or almost completely airless. This may be due to either a complete filling of the alveolar spaces with liquid and cells or to total collapse of potentially recruitable pulmonary units (atelectasis), or to a combination of both (6). Reticular pattern usually refers to discrete, recognizable linear thickening of the interstitium. This may be acute (edema or interstitial inflammation) or chronic (fibrosis) $(5,6)$.

\section{Early Phase [First Week]}

The most striking CT finding in early ALI/ARDS is the heterogeneous nature of the lung changes. One can conceptualize the lung in three components: (1) normal or near normal lung regions, most frequently located in nondependent lung (ventral in the supine position); (2) ground glass opacification in the middle lung; and (3) consolidation in the most dependent lung (dorsal in the supine position) $(2,3)$. Indeed, there is a vertical ventraldorsal gradient of densities, as previously suggested by Pistolesi and coworkers on chest $x$-ray (7) and previously described in experimental ALI/ARDS (8-10). In addition to the vertical density gradient, there is also a cephalocaudal gradient, with density increasing from the lung apex to the lung base $(2,11)$.

\section{Late Stage [Second Week and Beyond]}

ALI/ARDS is a dynamic process that follows a variable course, with a resolution within a week, or a more protracted course. Less than a week after the initial injury, the exudative phase changes to an organizing phase in which fluid is reabsorbed from the lung. The overall radiographic and CT density of the lung decreases and lung architecture undergoes extensive modification (Figure 2). In particular, with time, parenchymal fibrosis causes distortion of the interstitial and bronchovascular markings. Of note, beyond the first week or two, there is a dramatic increase of subpleural cysts or bullae (12). These emphysematous cysts or pneumatoceles vary from a few millimeters to several centimeters (13). These lesions, which are usually correlated with prolonged ventilation, have been reported both in the dependent (14) and in the nondependent lung $(13,15)$.
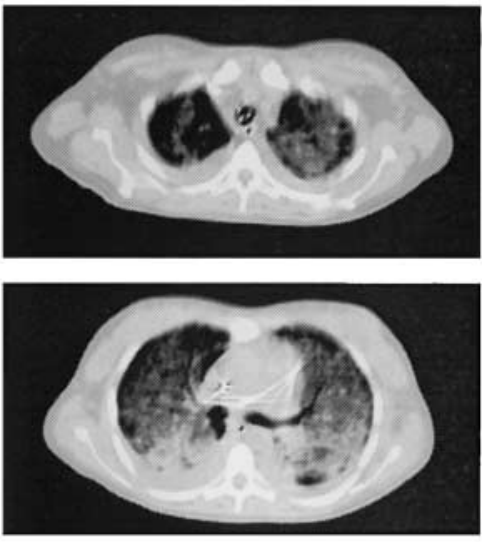

Figure 1. Anteroposterior chest $\mathrm{x}$-ray (right panel) and CT scansapex, hilum, and base-(left panels) in ARDS from sepsis. Images were taken at $5 \mathrm{~cm} \mathrm{H}_{2} \mathrm{O}$ end-expiratory pressure. The chest $x$-ray shows diffuse ground glass opacification, sparing the right upper lung. The $\mathrm{CT}$ scans show inhomogeneous disease and both

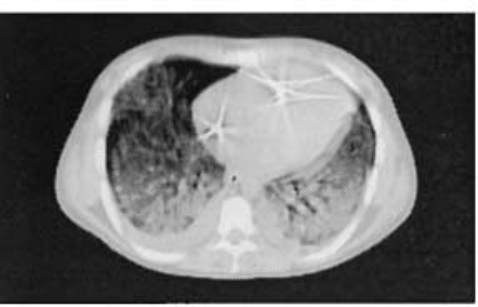
the craniocaudal and sternovertebral gradients.
The bullae may originate either from the cavitation of abscesses or from "volutrauma/barotrauma." In the first case, the bullae should follow the distribution of intraparenchymal infection. However, their formation may also be caused by ventilator-induced lung injury regardless of lung location (16). If found in the nondependent lung regions, one could postulate they were secondary to overdistention. If found in the mid-dependent lung regions, they could be due to shearing forces from airspace opening and closing in areas where lung was recruitable during inspiration, but the positive end-expiratory pressure (PEEP) applied was insufficient to keep them constantly open.

\section{Long-term Follow-up}

In patients who survive ALI/ARDS, a reticular pattern has been described in the nondependent most normal lung region. It has been found to correlate with the length of mechanical ventilation and with the use of inverse ratio ventilation (17). We believe that as with bullae, the location of fibrosis likely depends on the exposure to mechanical ventilation. The densely opacified region (the most dependent) may be not ventilated, and consequently not exposed to the trauma of mechanical ventilation (high fraction of inspired oxygen $\left[\mathrm{FI}_{\mathrm{O}_{2}}\right]$ and pressures). Accordingly, a negative correlation was noted between the extent of reticular pattern on the follow-up CT scan and the extent of intense opacification on initial CT scan. This suggests that fibrosis mainly occurs in the regions more exposed to mechanical ventilation.

\section{Pathogenesis Alters Morphology}

Recently, it has been shown that ALI/ARDS due to direct insult via the airway (aspiration, pneumonia) has different respiratory mechanics and a lower potential for recruitment than ALI/ARDS originating from an extrapulmonary focus via the bloodstream (primarily abdominal disease, sepsis) (18). With direct insult, one should expect multifocal involvement of the lung parenchyma, whereas with indirect insult, one should expect a more diffuse and uniform parenchymal alteration due to hematogenously distributed mediators. It has been shown experimentally that with indirect insult, the alteration is primarily interstitial (19). Moreover, as the indirect pulmonary 

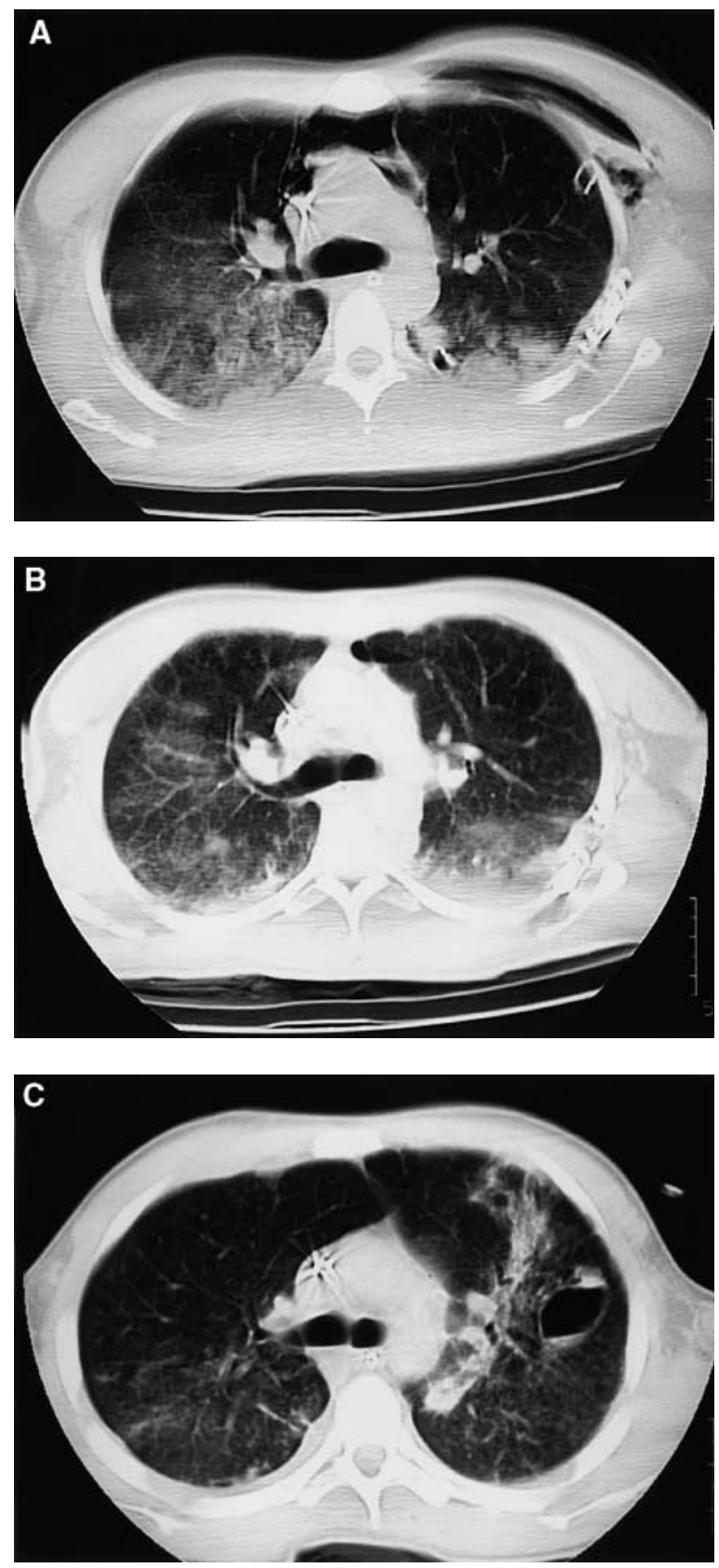

Figure 2. CT scans of ARDS patient due to multiple trauma. (A) CT scan through the carina $5 \mathrm{~d}$ after severe trauma shows diffuse ground glass opacification, right greater than left. There is a nondependent to dependent gradient. Incidentally noted is pneumomediastinum and a chest tube draining a pneumothorax. (B) Seven days later, there is partial clearing of both the diffuse ground glass opacification and the gravity-dependent atelectasis. The pneumomediastinum is almost completely resolved. (C) Five days later, ground glass opacification has a more reticular pattern. There is now a pneumatocele in the left midlung and increasing atelectasis adjacent to it.

insult is commonly due to abdominal diseases, basilar atelectasis increases due to the increased abdominal pressure from the cephalad shift of the diaphragm. Indeed, the morphological CT patterns in pulmonary and extrapulmonary ALI/ARDS should be somewhat different.

In fact, prospectively comparing 22 patients with early pulmonary ARDS $\left(\mathrm{ARDS}_{\mathrm{p}}\right)$ with 11 patients with early extrapulmonary ARDS $\left(\mathrm{ARDS}_{\mathrm{exp}}\right)$, Goodman and coworkers (20) found that $\mathrm{ARDS}_{\exp }$ had predominantly symmetric ground glass opacification and dorsal consolidation (atelectasis), whereas $\mathrm{ARDS}_{\mathrm{p}}$ tended to be asymmetric, with a mix of dense parenchymal opacification and ground glass opacification. Desai and coworkers (17), Winer-Muram and coworkers (21), and Rouby and coworkers (22) reached similar but not identical conclusions. Unfortunately, the available studies are somewhat limited. All report on a small number of patients. The time of ARDS onset to CT scanning is not uniform and respirator settings vary from study to study. Moreover, the ARDS $\mathrm{Axp}_{\text {group }}$ often included patients with abdominal disease and patients after cardiac surgery, in which the left lower lobe collapse is a frequent finding. In addition, direct and indirect insults may coexist (i.e., one or more lobes with the direct insult and both lungs with the indirect insult $[20,23])$, making the morphological pattern difficult to interpret.

\section{QUANTITATIVE ANALYSIS OF CT SCAN IMAGES}

The most relevant information on ALI/ARDS pathophysiology has been derived from the quantitative analysis of the $\mathrm{x}$-ray density of lung tissue depicted on the CT scan. Analysis is based, despite several sources of potential errors (24), as the range of electron energies from the source and variation in detector gain, on the close correlation between the x-ray attenuation in a given volume of tissue or voxel (the CT unit of volume) and the physical density of that volume of lung (i.e., the ratio of mass to the volume) (25). The x-ray attenuation of tissue is expressed by CT numbers, or Hounsfield units (HUs) (26). This CT number is obtained, in any given voxel, by determining the percentage of radiation absorbed by that volume of lung. As with any x-ray technique, the greater the absorption, the less radiation hitting the $\mathrm{x}$-ray film or CT detector. The attenuation scale arbitrarily assigns bone a value of $+1,000 \mathrm{HU}$ (complete absorption), air a value of $-1,000 \mathrm{HU}$ (no absorption), and water a value of $0 \mathrm{HU}$. Blood and tissue are 20-40 HU. Indeed, the relationship between the physical density, in any lung region of interest, assuming the specific weight of the tissue is equal to 1 , may be expressed as

$$
\begin{aligned}
& \text { volume }_{\text {gas }} /\left(\text { volume }_{\text {gas }}+\text { volume }_{\text {tissue }}\right)= \\
& \text { mean CT number } \\
& \text { observed }
\end{aligned}
$$

Rearranging Equation 1, it is possible to compute for any lung region of interest (contiguous voxels) in which the total volume is known, the volume of gas, the volume (and the weight) of tissue, and the gas/tissue ratio $(27,28)$.

For example, a voxel of $-1,000 \mathrm{HU}$ is exclusively composed of gas, a voxel with $0 \mathrm{HU}$ is exclusively composed of water (or "tissue"), and a voxel with $-500 \mathrm{HU}$ is composed of approximately $50 \%$ gas and $50 \%$ water (or tissue).

Several components contribute to the CT density of normal lung: the amount of alveolar gas $(1,000 \mathrm{HU})$, the amount of lung tissue and blood (20-40 HU), and the amount of water (0 HU). Because the physical density is a ratio, the same increase of density may derive from less gas or more tissue. In the early stages of ALI/ARDS, the alveolar gas content is decreased, and the "tissue" is increased because of interstitial and alveolar edema. Unfortunately, the voxel is a "black box" in which it is impossible to distinguish which component(s) are responsible for the $\mathrm{CT}$ density.

Because the CT unit of volume is the voxel, characterized by a CT number, it is worth considering what a voxel might include anatomically. This depends on the voxel dimension and the dimensions of the imaged lung. In the standard 10-mm ax- 
ial image (matrix size $256 \times 256$ ), the volume of a voxel $1.5 \times$ $1.5 \times 10 \mathrm{~mm}$ is $22.5 \mathrm{~mm}^{3}$, approximately the same volume as a normal acinus at functional residual capacity (about 16-22 $\mathrm{mm}^{3}$, including $\sim 2,000$ alveoli) (29). Thus, a voxel, considered as a fixed "CT pulmonary unit," may include, at functional residual capacity in normal lung, the same amount of the basic structures of a normal acinus (i.e., 2,000 alveoli, with about $29 \%$ gas in alveolar ducts, $61 \%$ gas in alveolar sacs, and $10 \%$ "tissue" barrier-capillaries). However, the basic structures included in one voxel derive from more than one acinus due to the different shape of the voxel (parallelepiped) and of the acinus (approximate sphere) and the fact that a voxel is unlikely to line up perfectly with an acinus. Other voxels may include more dense structures, such as arteries, veins, arterioles, venules, bronchial walls, and lymphatic vessels. In total, at functional residual capacity, considering all the lung structures, the gas is $\sim 70 \%$ and the "tissue" is $\sim 30 \%$. By increasing inflation, the voxel includes fewer structures because at $75 \%$ of total lung capacity, the acinus volume increases to $30-$ $40 \mathrm{~mm}^{3}$ (1 1/2-2 times greater than the voxel volume) (29). On the other hand, when normal acini completely collapse, losing all their gas, their volume consists only of the alveolar capillary barrier and blood, and up to 15-20 airless but otherwise normal acini may be included in one voxel. In the case of edema, when fluid completely replaces gas, the acinus dimensions remain normal, and one voxel should include approximately the same number of acini as under normal conditions. This is modeled in Figure 3. Current CT scanners are now capable of axial images as thin as $0.5 \mathrm{~mm}$ (compared with $10 \mathrm{~mm}$, greater matrix $-512 \times 512$ or $1,024 \times 1,024)$, and voxels would be proportionately smaller. Smaller voxels increase spatial resolution, decrease volume averaging, and improve the reliability of CT density readings.

\section{CT Frequency Distribution}

This analysis reveals how the "CT pulmonary units" (i.e., voxels) are distributed as a function of their physical density (the $\mathrm{CT}$ number). The CT number frequency distribution is usually performed on $11 \mathrm{CT}$ compartments (from $-1,000 \mathrm{HU}$ to +100 HU, each step of $100 \mathrm{HU}$ ), and the number of voxels included in each compartment is expressed as a percentage of the total number of voxels considered $(27,30)$. As shown in Figure 4, in normal subjects at functional residual capacity, about $50 \%$ of the "CT pulmonary units" are included in the compartment $-600 \mathrm{HU}$ to $-800 \mathrm{HU}$ (i.e., in average, $70 \%$ gas and $30 \%$ tissue). At total lung capacity, in normal subjects, $20 \%$ of the CT pulmonary units shift to the compartment between $-800 \mathrm{HU}$ and $-900 \mathrm{HU}$ (i.e., $85 \%$ gas and $15 \%$ tissue) (31). The $0 \mathrm{HU}$ compartment, in normal subjects, is negligible, and likely refers to voxels that image only solid or liquid lung structure, such as bronchial walls, pulmonary arteries, and veins whose dimensions are greater than one voxel.

Knowing the CT number frequency distribution of a given region of interest and its total volume (i.e., tissue + gas), it is possible to compute, rearranging Equation 1, the amount of tissue of each compartment. It is worth stressing that "tissue" includes not only lung tissue but also blood, extracellular water, cellular debris, etc. (i.e., all the material with a density around $0 \mathrm{HU}$ ).

\section{Lung Compartments}

To quantify lung regions with different aeration, two basic approaches are available. In the first, the density area, as it is seen morphologically (i.e., consolidation or ground glass), is estimated (visually or electronically) as a percentage of the total lung area studied (4). The second is based on the CT number frequency distribution of the lung, in which (Figure 4) a normally aerated voxel may be distinguished from a poorly or nonaerated voxel (30). Numerically, most authors define four lung compartments: hyperinflated, normally aerated, poorly aerated, and nonaerated. The HU limits of these compartments vary slightly from investigator to investigator $(2,30-35)$ (Table 1$)$.

Indeed, the hyperinflated compartment refers to the overfilling of the acini with gas. The "poorly aerated" compartment (which is approximately the quantitative equivalent of the ground glass pattern) refers to a gas/tissue ratio that is present also in normal subjects, at least at end expiration, but is more extensive in ALI/ARDS. The nonaerated compartment, in most cases, includes the voxels between $-100 \mathrm{HU}$ and $0 \mathrm{HU}$, that is, with a gas/tissue ratio from $1 / 10$ down to zero. This takes into account that in small airway collapse, some gas is left in the collapsed alveoli. When comparing the results of different authors, who used the same terminology (hyperaerated, normally aerated, poorly aerated, and nonaerated lung), it is important to also compare the CT cut-off points they used in their definitions. As an example, the hyperinflated compartment defined as $-1,000 \mathrm{HU}$ to $-900 \mathrm{HU}$ (32) is quite different from the hyperinflated compartment defined as $-1,000 \mathrm{HU}$ to $-800 \mathrm{HU}$ (35). Such variations may explain different or contrasting conclusions.

\section{CT SCAN PROTOCOLS AND ANALYSIS INFLUENCE RESULTS}

To compare different studies and to explain the reasons for some contradictory results, it is important to understand the limits of the different protocols and analyses used by different authors.

\section{One to Three Slices versus Whole Lung CT Scan}

Two basic CT scan protocols are described in the literature. The more traditional uses one to three axial images to infer the whole lung behavior. With the availability of faster CT scanners, whole lung reconstruction is now possible (31), and the value of the one to three images approach has been questioned (36). Both approaches have advantages and disadvantages (37). The one to three images approach allows multiple testing while limiting $\mathrm{x}$-ray exposure. Testing may be done at numerous levels of applied airway pressure, inspiration and expiration, different positions, etc. The limits of representative sampling are 2-fold: first, the more inhomogeneous the lung impairment, the less representative a few slices may be; second, it is impossible with this approach to scan exactly the same anatomical structure as the lung "moves" in different settings.

The continuous CT scanning of the entire lung is an ideal research tool, as it allows visualization of the entire lung and the study of lung levels using definite anatomical markers. However, it is difficult to rescan the entire patient under multiple test conditions because of x-ray exposure. In fact, the available studies of the entire lung have explored only two conditions ( 0 and 10 or $15 \mathrm{~cm} \mathrm{H}_{2} \mathrm{O}$ positive end-expiratory pressure [PEEP]). Indeed, the choice between the two approaches is a trade-off between more accurate information about few respiratory conditions and less accurate information about a much wider range of testing conditions.

\section{Recruitment}

The CT scan is a unique tool to differentiate between recruitment (aeration of previously gasless lung regions) and inflation (further aeration of already inflated lung regions). Since 1987, we defined recruitment as the difference in nonaerated tissue, expressed in grams, under different ventilatory conditions (30). Despite the limits of the one to three CT slices technique, this approach improved our understanding of PEEP 


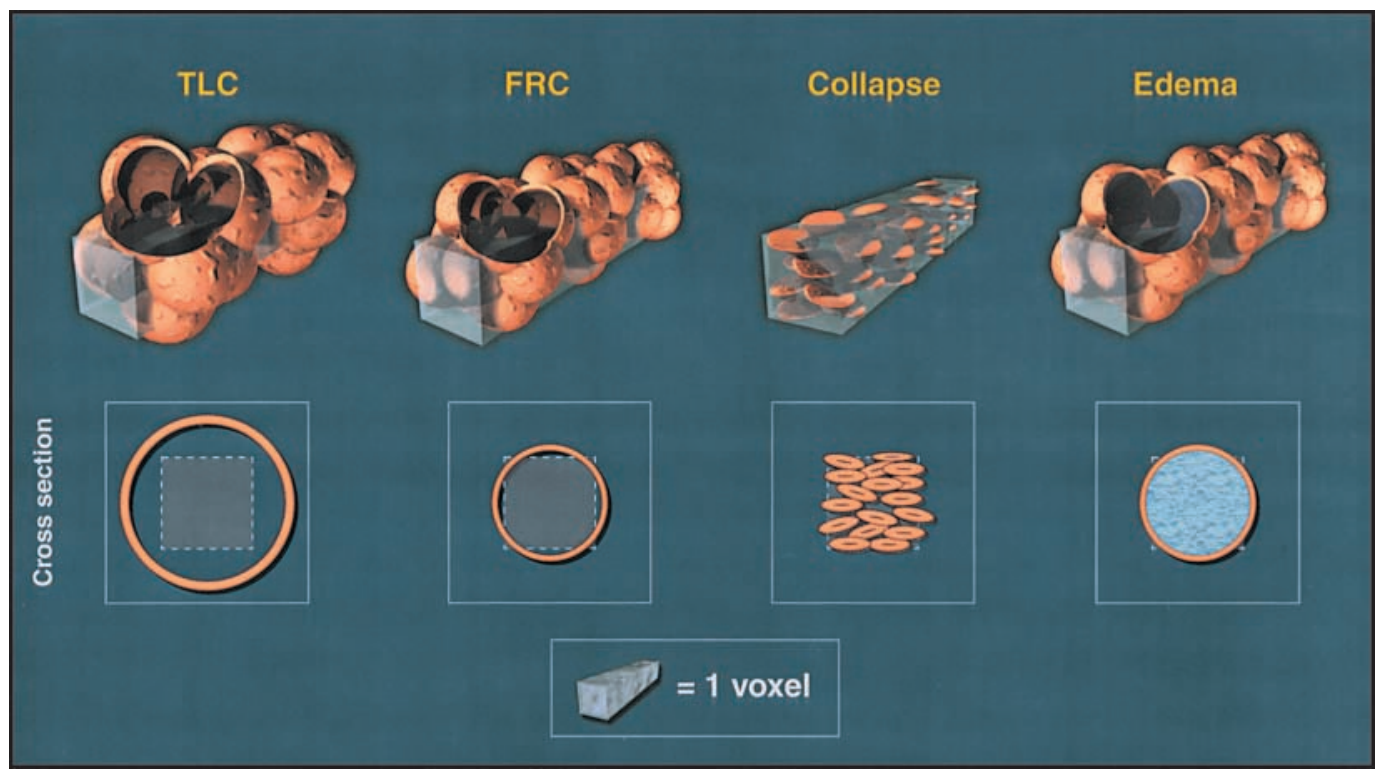

Figure 3. Relationship between the "CT pulmonary unit" and alveolar acini in normal condition at functional residual capacity (FRC), at two-thirds total lung capacity (TLC), with collapsed alveoli otherwise normal, and with edema.

mechanisms, the intratidal collapse and decollapse, and the interaction between end-inspiratory and end-expiratory collapse.

Recently, Malbouisson and coworkers (36) proposed a new method to compute recruitment, which takes into account not only the nonaerated tissue, but also the poorly aerated tissue, defining recruitment as the amount of gas that enters the poorly aerated and the nonaerated regions, when increasing the applied airway pressure.

The two approaches produce different results as they are intrinsically different. The first makes a clear distinction between recruitment (decrease in nonaerated tissue) and inflation, and the second identifies the quantity of gas introduced in the diseased lung (overall changes of aeration in nonaerated and poorly aerated tissue) (37). We believe it is not a question of which is better, but rather, they simply describe two different phenomena and, consequently, are not comparable.

\section{Hyperinflation and Overstretching}

In 1984, Hayhurst and coworkers reported that in emphysema there was a clear shift of the CT number frequency distribution toward the $-900 \mathrm{HU}$ to $-1,000 \mathrm{HU}$ range, "the hyperinflated compartment" (38). Indeed, there is little doubt that CT scan is a useful tool to detect hyperinflation. In ALI/ARDS patients,
Dambrosio and coworkers (35) found that above the upper inflection point of the volume-pressure curve, the number of voxels between $-1,000 \mathrm{HU}$ and $-800 \mathrm{HU}$ increased by $\sim 10 \%$. (Note: The cut-off of $-800 \mathrm{HU}$ is higher than the commonly used cutoff of -900 HU.) Vieira and coworkers (31) found that in six patients with ALI/ARDS, increasing pressure caused an increase of the hyperinflated compartment. The conclusion was that in ALI/ARDS, CT scan is a useful tool to detect "overdistention" due to mechanical ventilation. In a previous work (32), we found that in ALI/ARDS, at PEEP of $15 \mathrm{~cm} \mathrm{H}_{2} \mathrm{O}$, the $-1,000 \mathrm{HU}$ to $-900 \mathrm{HU}$ compartment was only $4 \%$ (i.e., in the range observed in normal subjects at functional residual capacity), and we concluded that hyperinflation was not found in ALI/ARDS. These apparently contradictory results derived, in our opinion, from the inappropriate use of the words "hyperinflation" and "overdistention or overstretching," which are often used incorrectly as synonyms. Actually, hyperinflation should refer to gas overfilling (i.e., gas/tissue ratio greater than 9/1), whereas overdistention and overstretching should refer to the alveolar wall tension (pressure). In severe ARDS, in which the whole lung has an increased mass, the increased pressure may result in overdistention, but the critical number of $-900 \mathrm{HU}$ is not reached. Indeed, it is important to recognize that a lung may

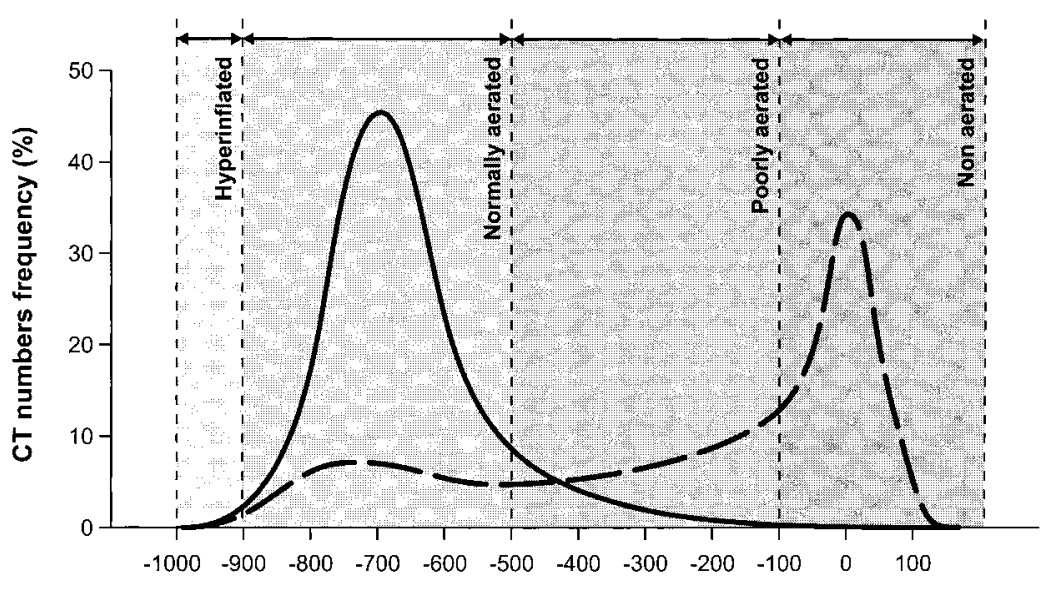

CT numbers (Hounsfield Units)
Figure 4. The lung compartments, as defined by CT numbers, in normal condition (solid line) and in typical ALI/ ARDS (dashed line). For further details, see also Table 1. 
TABLES 1. HOUNSFIELD UNITS RANGE OF DIFFERENT KINDS OF LUNG TISSUE

\begin{tabular}{lllll}
\hline & & \multicolumn{2}{c}{ Tissue } \\
\cline { 2 - 4 } & Nonaerated & Poorly Aerated & Normally Aerated & Hyperinflated \\
\hline Gattinoni and coworkers (1986) (2) & $+100 /-400^{*} \mathrm{HU}$ & - & $-400 /-100 \mathrm{HU}$ \\
Gattinoni and coworkers (1987) (30) & $+100 /-100 \mathrm{HU}$ & $-100 /-500 \mathrm{HU}$ & $-500 /-900 \mathrm{HU}$ & - \\
Gattinoni and coworkers (1988) (32) & $+100 /-100 \mathrm{HU}$ & $-100 /-500 \mathrm{HU}$ & $-500 /-900 \mathrm{HU}$ & $-900 /-1,000^{\dagger} \mathrm{HU}$ \\
Puybasset and coworkers (1995) (33) & Visually estimated & - & - & - \\
Umamaheswara Rao and coworkers (1997) (34) & $+100 /-100 \mathrm{HU}$ & $-100 /-500 \mathrm{HU}$ & $-500 /-1,000 \mathrm{HU}$ & - \\
Dambrosio and coworkers (1997) (35) & $+100 /-150 \mathrm{HU}$ & - & $-150 /-800^{\ddagger} \mathrm{HU}$ & $-800 /-1,000 \mathrm{HU}$ \\
Vieira and coworkers (1998) (31) & $+100 /-100 \mathrm{HU}$ & $-100 /-500 \mathrm{HU}$ & $-500 /-900 \mathrm{HU}$ & $-900 /-1,000 \mathrm{HU}$ \\
\hline
\end{tabular}

Definition of abbreviation: HUs = Hounsfield units.

* "Pathological areas."

† "Overdistended."

‡"Normally (or poorly)."

be overdistended and not hyperinflated (as in severe ARDS) and vice versa (as in emphysema).

\section{STRUCTURE-FUNCTION CORRELATION IN THE WHOLE LUNG}

\section{Gas Exchange}

In most studies, the amount of nonaerated tissue seen on CT ( 0 to $-100 \mathrm{HU})$ and its variation have correlated well with hypoxemia and shunt fraction $(20,32,39-41)$. These results were also observed in normal subjects during paralysis and anesthesia (42). Although the relationship between hypoxemia and the nonaerated tissue seen on CT is straightforward, the role of the poorly aerated tissue $(-500$ to $-100 \mathrm{HU})$ in the development of hypoxemia is not. The poorly aerated tissue or ground glass opacification alone does not correlate with hypoxemia $(14,20,30)$, whereas, taken together, both ground glass and consolidation $(20,35)$ and poorly and nonaerated tissue (36) do correlate with hypoxemia.

In our opinion, a definitive understanding of the gas exchange-lung structure relationship will be possible only when regional perfusion is measured as well. In fact, with the CT scan, it is possible to measure the aeration of only a given region. There is little doubt that the nonaerated compartment is a shunt region. We do not know, however, to what degree it is perfused. On the other hand, the "poorly aerated tissue" compartment (gas/tissue ratio between $1 / 10$ and 5/5) should be capable of oxygenating the blood. At high $\mathrm{FI}_{\mathrm{O}_{2}}$, its contribution to hypoxemia should decrease. Unfortunately, we do not know the perfusion of each compartment. Similarly, we do not know the dynamics of ventilation in a given lung region. In fact, the CT scan provides information on static inflation only; it does not directly measure regional ventilation. The normally aerated compartment, as an example, if perfused and overdistended, should normally exchange oxygen, through a sort of "apneic oxygenation," but would be unable to normally exchange carbon dioxide, due to the decreased ventilation.

Despite our lack of knowledge of the anatomic distribution of regional ventilation and perfusion in ALI/ARDS, there is strong evidence that, at least, the nonaerated compartment is the region of shunt, and its reexpansion is usually associated with increased oxygenation (32).

\section{Lung Mechanics}

The most important information from the CT analysis of ALI/ ARDS is derived from the study of the relationship between the CT data and the lung mechanics. Until 1986, in fact, it was a common belief, with some exception (43), that the ALI/ARDS lung was "stiff" because of the low compliance of the respiratory system.

Unexpectedly, it was found that respiratory compliance was not related to the amount of nonaerated or poorly aerated tissue, but it was closely associated with the amount of normally aerated tissue, which receives most of the insufflated gas. Thus, the respiratory compliance in early ALI/ARDS appears to be a direct measure of normally aerated tissue (30), suggesting that in ALI/ARDS, the aerated lung was not "stiff," but rather it was small (the "baby lung").

\section{CT-REGIONAL ANALYSIS}

The most relevant information on ALI/ARDS physiopathology derives from regional lung analysis, which is performed by dividing each $\mathrm{CT}$ axial image into 10 equally spaced intervals, from sternum to vertebra. At each lung interval, the same analysis described for the whole lung is applied. In fact, knowing the volume of each level and its physical density (in HU), it is possible to compute the regional lung tissue and gas volumes and gas/tissue ratio $(44,45)$. Moreover, assuming that the pressure (weight) is transmitted to the dependent lung parenchyma as in a fluid, it is possible to compute, at each lung interval along the sternovertebral axis, the pressure exerted by the tissue above. The superimposed pressure is then estimated by multiplying the density by the height (46).

Accordingly:

$$
\mathrm{SP}_{\text {level }}=[1-(\mathrm{CT} /-1,000)] \times \mathrm{Ht}+\mathrm{SP}_{\text {above levels }}
$$

where CT is the mean CT number of the given level and $\mathrm{Ht}$ is the height of that level.

\section{Edema Distribution and Lung Volume}

As shown in Figure 5, we found that the tissue mass, measured in each of the 10 lung levels along the sternovertebral axis, was almost double the normal mass at that level (46). This suggests that edema (i.e., the excess tissue mass compared with the normal subjects) is evenly distributed throughout the lung parenchyma, as found in the experimental setting $(47,48)$ and in ALI/ ARDS, using the positron emission tomography (PET) technique (49). Lung size, in its anteroposterior dimension, is similar in ALI/ARDS patients and in normal subjects, suggesting that, at least in this projection, the edema replaces an equal amount of gas space, maintaining lung volume (gas volume + tissue volume). Puybasset and colleagues (11), using contiguous spiral CT images from apex to base and multiplanar reconstructions, found, as we did, an unmodified anteroposterior lung volume, but they observed an $\sim 15 \%$ decrease of the cephalocaudal dimensions of the lung in ALI/ARDS (see below).

\section{Superimposed Pressure and PEEP}

The CT regional analysis, showing the nongravitational distribution of the edema, is in apparent contradiction to the equal gravitational distribution of densities. As the excess tissue mass 
is not greater in the dependent regions, the only explanation for the gravitational density increase is a decrease of the gas content along the sternovertebral axis $(46,50)$. This nondependent to dependent decrease in regional inflation and increased CT density is also found in normal subjects (51). It has been attributed to several factors: the thoracic shape, the lung weight, and the gravitational distribution of the blood in the lung capillaries (24). All these factors increase the pleural pressure along the vertical axis, decreasing the transpulmonary pressure (airways pressure - pleural pressure) that is the distending force of the lung. The normal vertical pleural pressure gradient in the supine position (which equals the transpulmonary pressure gradient) is of the order of $2-3 \mathrm{~cm} \mathrm{H}_{2} \mathrm{O}$ (52), the same gradient as the superimposed pressure. In ALI/ARDS, the thoracic shape in its anteroposterior dimension is similar to normal (11, 46). There is also no evidence that blood accumulates excessively in the dependent lung regions. In fact, the excess tissue mass in which the "excess blood" should be included is not higher than in nondependent lung regions. Indeed, whereas the thoracic shape and blood distribution are fairly constant, what changes in ALI/ARDS is the superimposed pressure (weight of the lung), which is doubled or tripled compared with normal (Figure 5). Recent experimental work has shown that the superimposed pressure changes, as measured by CT scan, are strictly correlated with pleural pressure changes, measured directly at various lung levels in the pleural space (40).

The increase of superimposed pressure primarily accounts for redistribution of lung densities in the prone position (Figure 6), as the gravitational forces are inverted (44). This explains, at least in part, the mechanism of PEEP (45). In fact, we were able to show that PEEP effectively counteracts the superimposed pressure. To keep open the most dependent lung regions, a PEEP equal to or greater than the superimposed pressure on that region must be applied. In the middle lung, where the superimposed pressure is reduced, less PEEP is necessary to keep the lung open, and no PEEP is required to keep open the nondependent lung regions, as no compressive forces are present in this part of the lung parenchyma.

These findings led to the concept of the sponge model: the ALI/ARDS lung increases its own permeability in each region with an even distribution of edema, and the increased lung mass causes the lung collapse under its own weight (53) (Figure 5). However, the sponge model does not explain the entire ALI/ ARDS lung behavior, as this compressive force is not the only one inducing lung collapse. In the ideal "sponge model," in fact, the total lung volume (gas + tissue) should be unmodified, with substitution of gas by edema. From the work of Puybasset and coworkers (11), we know that in ALI/ARDS the maximal lung volume loss is caudal, close to the diaphragm. There is a craniocaudal gradient as well as a ventrodorsal gradient. This suggests that the decrease of transpulmonary pressure at the lung base is not just due to the superimposed pressure. It is likely that the heart weight (more important in the supine than in the prone position) $(54,55)$ and the increased abdominal pressure, as frequently found in ALI/ARDS of extrapulmonary origin (18), also contribute to the caudal atelectasis.

The lung sponge model theory, that is, increased interstitial edema and progressive deaeration along the ventrodorsal axis due to the superimposed pressure, has been recently challenged. Wilson and coworkers (56), on the basis of previous experimental works (57) in which regional volumes were measured by markers, proposed the following model: in the edematous lung, the pressure first causes the air-fluid interface to penetrate in the mouth of the alveoli (airway pressure around $20 \mathrm{~cm} \mathrm{H}_{2} \mathrm{O}$ ), then the air-fluid interface is inside the alveoli and the lung becomes compliant. The basic difference between the two views is that in the sponge model the edema is believed to be predominantly in the interstitium (causing alveolar collapse by compression), whereas in the air-fluid interface model, the edema is predominantly in the alveoli. In both models, the total lung volume is nearly normal.

\section{THE CT SCAN AND MECHANICAL VENTILATION SETTINGS}

\section{Opening the Lung}

One of the cornerstones of the lung protective strategy is lung opening. It has been thought that lung opening primarily occurs around the lower inflection point of the volume-pressure curve (58). However, it has long been known that oxygenation and compliance improve when high tidal volumes (and pressures) are applied (59). More recently, first on theoretical grounds and mathematical modeling $(60,61)$ and then in the clinical setting $(62,63)$, it has been suggested that recruitment likely occurs along the entire volume-pressure curve. This is well above the lower inflection point, as suggested by the classical physiology of healthy lung (64).

The CT scan provided the direct evidence that recruitment is a pan-inspiratory phenomenon (Figure 7). In fact, recent work has helped explain recruitment along the volume-pressure curve, both in the experimental setting (oleic acid-dogs) (40) and in patients with ALI/ARDS (41). Recruitment occurs along the entire volume-pressure curve well above the lower inflection point and even above the upper inflection point, with a definite spatial distribution (ventral to dorsal and cephal to caudal) $(11,40,41)$. The "sigmoid" shape of the recruitment pressure curve implies a gaussian distribution of opening pressures. In other words, as previously suggested on theoretical arguments (60) and clinical inferences (65), it appears that in ALI/ARDS lung there are regions with different opening pressures, which range from a few $\mathrm{cm} \mathrm{H}_{2} \mathrm{O}$ to $45-70 \mathrm{~cm} \mathrm{H}_{2} \mathrm{O}(40,41)$. This range is likely due to differing types of atelectasis. In fact the opening pressure for small airway collapse (typical of the compression atelectasis) is of the order of $20 \mathrm{~cm} \mathrm{H}_{2} \mathrm{O}$ (loose atelectasis),
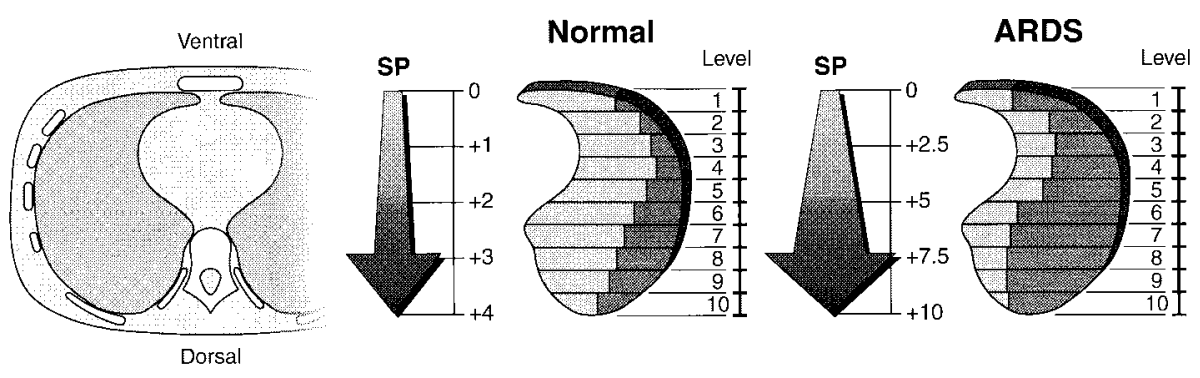

Figure 5. Schema representation of sponge model. In ARDS the "tissue," likely edema in the early phase, is almost doubled in each lung level compared with normal, indicating the nongravitational distribution of edema. The increased mass, however, causes an increased superimposed pressure (SP), which, in turn, leads to a "gas squeezing" from the most dependent lung regions. Superimposed pressure is expressed as $\mathrm{cm} \mathrm{H} \mathrm{H}_{2} \mathrm{O}$. The values indicated in the figures are taken from Pelosi and coworkers (46). 
whereas the opening pressure required to open alveolar collapse is of the order of $30-40 \mathrm{~cm} \mathrm{H}_{2} \mathrm{O}$ (sticky atelectasis) (66). In normal lung, Rothen and coworkers (67) found that the pressure required to clear the compression atelectasis developed during anesthesia and paralysis was in the order of $40 \mathrm{~cm} \mathrm{H}_{2} \mathrm{O}$.

It is important to emphasize, however, that the true opening pressure is the transpulmonary pressure (i.e., the applied airway pressure minus the pleural pressure). With high chest wall elastance and high pleural pressure (as in obesity or, often, in ALI/ARDS originating from abdominal disease) the airway pressure required to reach a sufficient transpulmonary pressure may be higher than $40-45 \mathrm{~cm} \mathrm{H}_{2} \mathrm{O}$. The main message from these studies, however, is that in ALI/ARDS a wide range of opening pressures is distributed throughout the lung.

\section{Interaction between End Expiration and End Inspiration}

As previously discussed, the increased superimposed pressure decreases the transpulmonary pressure, causing a progressive

\section{End Expiration}
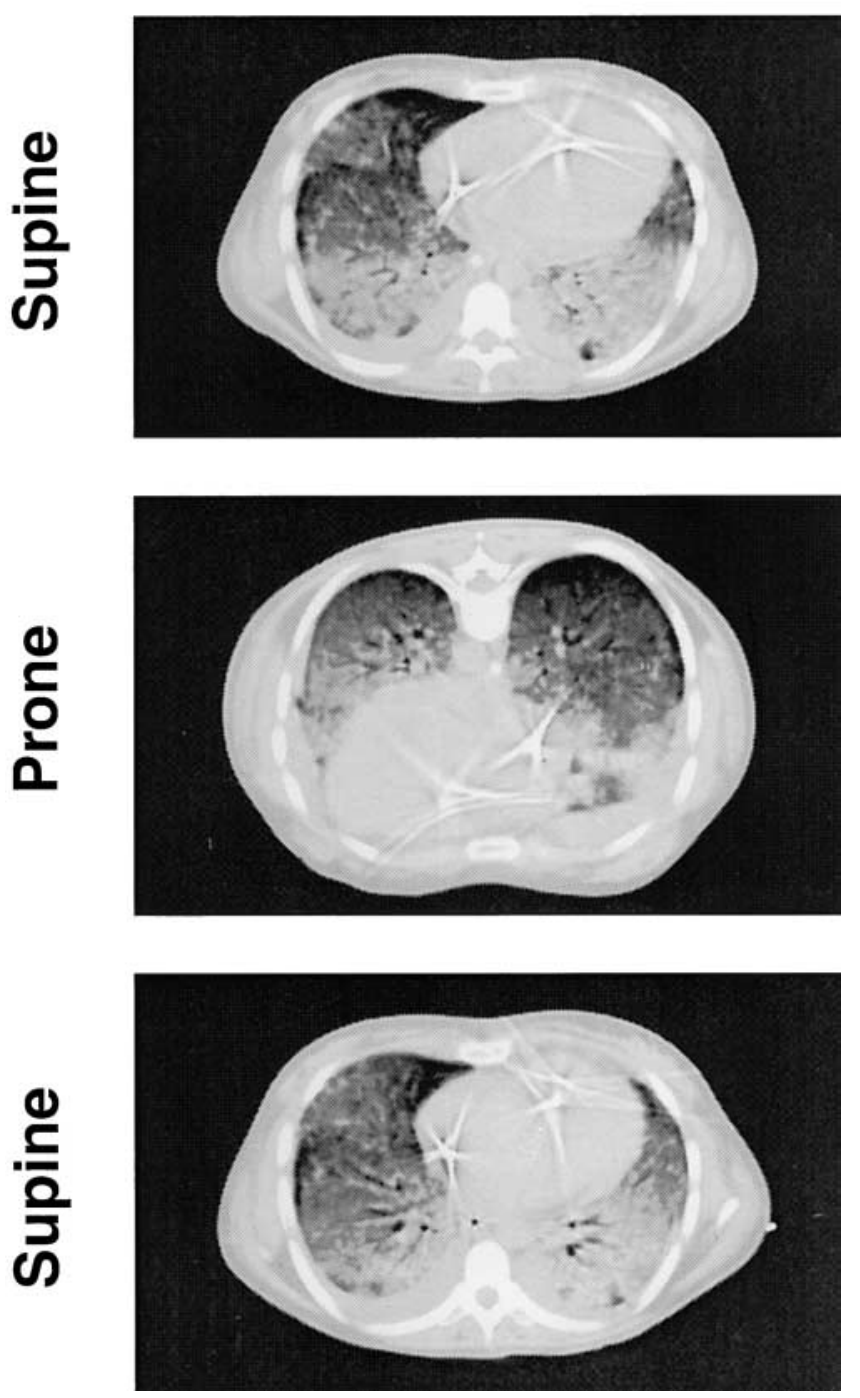

Figure 6. CT images of ARDS in supine (upper panel), prone (middle panel), and return to supine position (lower panel). The CTs were taken at end expiration and $10 \mathrm{~cm} \mathrm{H}_{2} \mathrm{O}$ PEEP. Note how gravity-dependent densities shift from dorsal to ventral within minutes when the patient is turned prone. deaeration along the ventrodorsal gradient. Positive end-expiratory pressure counteracts the compressive forces, keeping the lung open. This would imply that in a given lung and at a given PEEP, a fixed amount of lung stays open, independent of the previous lung history. However, the end-expiratory collapse, at a given PEEP, depends on the previous inspiration, suggesting that the end-expiratory and end-inspiratory collapses are not independent phenomena $(40,41)$. The CT scan provides evidence that they are closely related. In fact, the end-expiratory collapse is greater when the previous inspiratory plateau pressure is lower, in both dogs (oleic acid) and in patients with ALI/ ARDS. This indicates that what stays open with PEEP is only what has been opened by the preceding inspiratory pressure. In addition, the lung stays open only if the superimposed pressure is lower than the PEEP applied. If the superimposed pressure is greater than PEEP, whatever has been opened by the inspiratory plateau pressure would collapse at end expiration.

These findings emphasize the concept that PEEP is an endexpiratory maneuver, which keeps the lung open at a given level, depending on the previous inspiratory opening and superimposed pressure. Indeed, choosing a PEEP level based on the inspiratory limb of the pressure-volume curve does not appear to have a solid physiopathological basis.

\section{Distribution of Gas in Mechanical Ventilation}

The CT scan taken at end inspiration is dramatically different than at end expiration. Again, quantitative analysis provides the most relevant information. In fact, at the same tidal volume of 10 $\mathrm{ml} / \mathrm{kg}$, it was found that increasing PEEP from 0 to $20 \mathrm{~cm} \mathrm{H}_{2} \mathrm{O}$ (and plateau pressure from 21 to $46 \mathrm{~cm} \mathrm{H}_{2} \mathrm{O}$ ) causes a progressively more homogeneous distribution of ventilation (68). This appears to be related to two phenomena. First, the nondependent lung regions become less compliant, likely due to stretching of already open pulmonary units. Second, the dependent lung regions become more compliant. At PEEP of $15 \mathrm{~cm} \mathrm{H}_{2} \mathrm{O}$ and 20 $\mathrm{cm} \mathrm{H}_{2} \mathrm{O}$ most of the pulmonary units, previously collapsed, stay open, and may "accept" the delivered gas. The more homogeneous ventilation is usually associated with better oxygenation, and these "indirect" PEEP effects (i.e., the changes in the regional compliance) may be another mechanism through which PEEP improves oxygenation. This secondary effect may be important in late ARDS, when compression atelectasis is less likely and the primary effect of PEEP (i.e., counteracting the superimposed pressure) is likely reduced or absent.

\section{Intratidal Collapse and Decollapse}

It has been recognized that in both the experimental (69-71) and the clinical setting (72), the mechanical opening and closing of pulmonary units through the respiratory cycle may cause lung "barotrauma/volutrauma/biotrauma," releasing inflammatory mediators that are potentially harmful to the lung. The CT scan has provided direct evidence of opening and closing. We found that at plateau pressures of 21 to $46 \mathrm{~cm} \mathrm{H}_{2} \mathrm{O}$, most of the recruitment is accomplished (68). However, what stays open then depends on the PEEP level. In this series of patients, only 15 and $20 \mathrm{~cm} \mathrm{H}_{2} \mathrm{O}$ PEEP were sufficient to keep the acini open that were recruited at a higher plateau pressure. Thus, the CT scan confirms that after the recruitment maneuver causes complete opening, very high plateau pressure is not necessary. Rather, PEEP just has to be kept high enough to prevent end-expiratory collapse.

\section{THE IMPACT OF CT SCANNING ON CLINICAL PRACTICE}

As CT scanners have become faster, and more generally available, they are playing an increasing role in the diagnosis and 


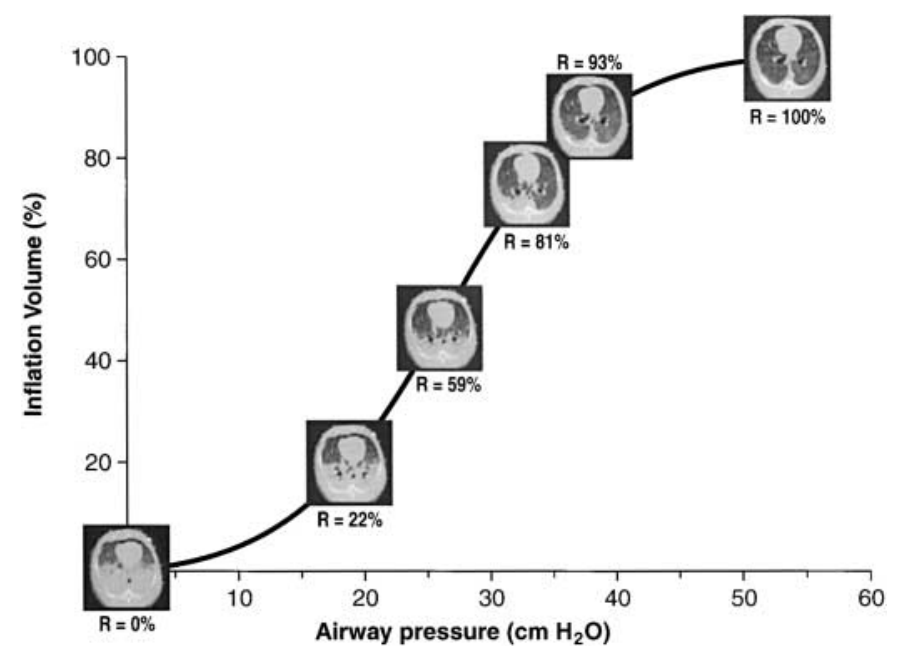

Figure 7. Recruitment in an experimental ARDS model (oleic acid in dogs), as a function of the applied airway pressures. Recruitment occurs along the entire volume-pressure curve, even after the upper inflection point. " $R$ " indicates the percentage of recruitment occurring at the corresponding airway pressure. The data were fitted with a sigmoid function, according to Venegas and coworkers (60). Rearranged from Pelosi and coworkers (40). Similar results were obtained in patients (41).

management of patients with acute respiratory disease (12). Cross-sectional images provide better tissue discrimination and eliminate the superimposition of structures, which is inherent in conventional radiography. In a retrospective study of 74 patients with ALI/ARDS, Tagliabue and coworkers (73) showed that pleural effusion, lobar atelectasis, lung abscesses, acute pneumothoraces, barotrauma, and unsuspected to be malpositions were seen more often, and more definitively, on CT than on chest x-ray. CT yielded additional information in $66 \%$ and influenced treatment in 22\%. Desai and Hansell (74) indicate that CT is best used to detect occult complications in patients who are deteriorating, or not improving at the expected rate.

The advantages of CT must be balanced against potential risks of transporting critically ill patients, additional costs, and the additional radiation dose. In agreement with Desai and Hansell (74), we believe that CT is best reserved for solving clinical dilemmas rather than for routine imaging.

The more controversial use of CT is in conjunction with the initiation of mechanical ventilation. Early in the course of ALI/ARDS, CT is helpful in assessing the nature and extent of the patients' infiltrates and their response of mechanical ventilation. To limit radiation, the lung is usually imaged at two or three levels, repeating the same levels at different ventilator settings (e.g., end inspiration and at different PEEP levels). The use of different pressures helps to distinguish between areas of alveolar collapse and consolidation, providing helpful information about mechanical ventilation parameters.

\section{NEW DEVELOPMENTS AND FUTURE AREAS OF RESEARCH}

Electron beam CT and new multidetector helical scanners can now obtain axial images at subsecond speed (50-500 ms) and reduced radiation, overcoming some of the technical limitations and radiation concerns of traditional CT scanners. This increased speed can be used to scan continuously over a fixed area of lung or to image the entire lung, apex to base, in less than $5 \mathrm{~s}$ and at reduced patient dose.

If the CT table is held at a fixed position, continuous rapid scans of the lung can be obtained during the respiratory cycle.
Because the lung inflates and deflates at different rates, and local pathology alters inflation and deflation, cine viewing or sophisticated computer analysis will be needed to provide subsecond understanding of ventilatory dynamics (75). Imaging can be prospectively, or retrospectively, gated to analyze specific phases of the respiratory cycle (76).

Fast scanning will also overcome the problem of the craniocaudal lung misregistration during respiration. If a single detector scanner is held in a fixed location, CT will "image" different lung levels during the respiratory cycle, making precise quantitative comparisons impossible. Multidetector and electron beam computed tomography (EBCT) scanners can rapidly scan through contiguous slices (a volume of tissue), making it possible to perfectly match anatomic areas throughout the respiratory cycle.

Although CT has been helpful in understanding ventilatory dynamics, it has not been used to analyze lung perfusion in ALI/ARDS. Without appropriately analyzing regional lung perfusion, and how it relates to regional ventilation and morphological abnormalities, CT scanning provides an incomplete understanding of ALI/ARDS. PET scanning and magnetic resonance imaging (MRI) scanning, on the other hand, have been used to assess both intraparenchymal water, capillary permeability, and capillary blood flow $(77,78)$. Just marketed machines combine CT and PET scanning into one unit, providing precise anatomic correlation between the physiological data of PET and the anatomic data of CT. Three-dimensional, rather than two-dimensional data will be available. Recently, electron beam CT has been used to assess pulmonary perfusion and correlate with lung morphology $(79,80)$. Hopefully, these technical marriages will facilitate a marriage of our understanding of regional ventilation and perfusion.

\section{References}

1. Rommelsheim K, Lackner K, Westhofen P, Distelmaier W, Hirt S. Das respiratorische Distress-Syndrom des Erwachsenen (ARDS) im Computertomogramm. Anasth Intensivither Noftallmed 1983;18:59-64.

2. Gattinoni L, Mascheroni D, Torresin A, Marcolin R, Fumagalli R, Vesconi S, Rossi GP, Rossi F, Baglioni S, Bassi F, et al. Morphological response to positive end expiratory pressure in acute respiratory failure. Computerized tomography study. Intensive Care Med 1986;12:137-142.

3. Maunder RJ, Schuman WP, McHugh JW, Marglin SI, Butler JB. Preservation of normal lung regions in the adult respiratory distress syndrome. Analysis by computed tomography. JAMA 1986;255:2463-2465.

4. Brismar B, Hedenstierna G, Lundquist H, Strandberg A, Svensson L, Tockics L. Pulmonary densities during anesthesia with muscolar relaxation. A proposal of atelectasis. Anesthesiology 1985;62:422-428.

5. Austin JHM, Müller NL, Friedman PJ, Hansell DM, Naidich DP, RemyJardin M, Webb WR, Zerhouni EA. Glossary of terms for CT of the lungs: recommendations of the nomenclature committee of the Fleischner Society. Radiology 1996;200:327-331.

6. Remy-Jardin M, Remy J, Giraud F, Wattinne L, Gosselin B. Computed tomography assessment of ground-glass opacity: semiology and significance. J Thorac Imag 1993;8:249-264.

7. Pistolesi M, Miniati M, Milne EN, Giuntini C. The chest roentgenogram in pulmonary edema. Clin Chest Med 1985;6:315-344.

8. Hedlund LW, Effmann EL, Bates WM, Beck JW, Goulding PL, Putman CE. Pulmonary edema: a CT study of regional changes in lung density following oleic acid injury. J Comput Assist Tomogr 1982;6:939-946.

9. Slutsky RA, Long S, Peck WW, Higgins CB, Mattrey R. Pulmonary density distribution in experimental noncardiac canine pulmonary edema evaluated by computed transmission tomography. Invest Radiol 1984; 19:168-173.

10. Hedlund LW, Vock P, Effmann EL, Putman CE. Morphology of oleic acid-induced lung injury observations from computed tomography, specimen radiography, and histology. Invest Radiol 1985;20:2-8.

11. Puybasset L, Cluzel P, Chao N, Slutsky AS, Coriat P, Rouby JJ, and the CT Scan ARDS Study Group. A computed tomography scan assessment of regional lung volume in acute lung injury. Am J Respir Crit Care Med 1998;158:1644-1655. 
12. Goodman LR. Congestive heart failure and adult respiratory distress syndrome. New insights using computed tomography. Radiol Clin North Am 1996;34:33-46.

13. Rouby JJ, Lherm T, Martin de Lassale E, Poète P, Bodin L, Finet JF, Callard P, Viars P. Histologic aspects of pulmonary barotrauma in critically ill patients with acute respiratory failure. Intensive Care Med 1993;19:383-389.

14. Gattinoni L, Bombino M, Pelosi P, Lissoni A, Pesenti A, Fumagalli R, Tagliabue M. Lung structure and function in different stages of severe adult respiratory distress syndrome. JAMA 1994;271:1772-1779.

15. Churg A, Golden J, Fligiel S, Hogg JC. Bronchopulmonary displasia in the adult. Am Rev Respir Dis 1983;127:117-120.

16. Goldstein I, Bughalo MT, Marquette CH, Lenaour G, Lu Q, Rouby JJ, and the experimental ICU Study Group. Mechanical ventilationinduced air-space enlargement during experimental pneumonia in piglets. Am J Respir Crit Care Med 2001;163:958-964.

17. Desai SR, Wells AU, Rubens MB, Evans TW, Hansell DM. Acute respiratory distress syndrome: CT abnormalities at long-term follow up. Radiology 1999;210:29-35.

18. Gattinoni L, Pelosi P, Suter PM, Pedoto A, Vercesi P, Lissoni A. Acute respiratory distress syndrome caused by pulmonary and extrapulmonary disease. Am J Respir Crit Care Med 1998;158:3-11.

19. Müller-Leisse C, Klosterhalfen B, Hauptmann S, Simon HB, Kashefi A, Andreopoulos D, Kirkpatrick CJ, Günther RW. Computed tomography and histologic results in the early stages of endotoxin-injured pig lungs as a model for adult respiratory distress syndrome. Invest Radiol 1993;28:39-45.

20. Goodman LR, Fumagalli R, Tagliabue P, Tagliabue M, Ferrario M, Gattinoni L, Pesenti A. Adult respiratory distress syndrome due to pulmonary and extrapulmonary causes: CT, clinical, and functional correlation. Radiology 1999;213:545-552.

21. Winer-Muram HT, Steiner RM, Gurney JW, Shah R, Jennings SG, Arheart KL, Eltorky MA, Meduri GU. Ventilator-associated pneumonia in patients with adult respiratory distress syndrome: CT evaluation. Radiology 1998;208:193-199.

22. Rouby JJ, Puybasset L, Cluzel P, Richecoeur J, Lu Q, Grenier P, and the CT Scan ARDS Study Group. Regional distribution of gas and tissue in acute respiratory distress syndrome. II. Physiological correlations and definition of an ARDS Severity Score. Intensive Care Med 2000; 26:1046-1056

23. Tutor JD, Mason CM, Dobard D, Beckerman RC, Summer WR, Nelson S. Loss of compartmentalization of alveolar tumor necrosis factor after lung injury. Am J Respir Crit Care Med 1994;149:1107-1111.

24. Dummon GB. Computed tomography and pulmonary measurements. Br J Anaesth 1998;80:665-671.

25. Mull RT. Mass estimates by computed tomography. Physical density from CT numbers. AJR Am J Roentgenol 1984;143:1101-1104.

26. Hounsfield GN. Computerized transverse axial scanning (tomography): Part I. Description of system. Br J Radiol 1973;46:1016-1022.

27. Gattinoni L, Pesenti A, Torresin A, Baglioni S, Rivolti M, Rossi F, Scarani F, Marcolin R, Cappelletti G. Adult respiratory distress syndrome profiles by computed tomography. J Thorac Imag 1986;1:25-30.

28. Gattinoni L, Pelosi P, Pesenti A, Brazzi L, Vitale G, Moretto A, Crespi A, Tagliabue M. CT scan in ARDS: clinical and physiopathological insights. Acta Anasthesiol Scand 1991;95:87-94.

29. Weibel ER. Airways and blood vessels. In: Weibel ER, editor. The pathway for oxygen. Structure and function in the mammalian respiratory system. Cambridge: Harvard University Press; 1984. p. 272-301.

30. Gattinoni L, Pesenti A, Avalli L, Rossi F, Bombino M. Pressure-volume curve of total respiratory system in acute respiratory failure. Computed tomographic scan study. Am Rev Respir Dis 1987;136:730-736.

31. Vieira SRR, Puybasset L, Richecoeur J, Lu Q, Cluzel P, Gusman PB, Coriat P, Rouby JJ. A lung computed tomographic assessment of positive end-expiratory pressure-induced lung overdistention. Am J Respir Crit Care Med 1998;158:1571-1577.

32. Gattinoni L, Pesenti A, Bombino M, Baglioni S, Rivolta M, Rossi F, Rossi G, Fumagalli R, Marcolin R, Mascheroni D, et al. Relationships between lung computed tomographic density, gas exchange, and PEEP in acute respiratory failure. Anesthesiology 1988;69:824-832.

33. Puybasset L, Rouby JJ, Mourgeon E, Cluzel P, Souhil Z, Law-Koune JD, Stewart T, Devilliers C, Lu Q, Roche S, et al. Factors influencing cardiopulmonary effects of inhaled nitric oxide in acute respiratory failure. Am J Respir Crit Care Med 1995;152:318-328.

34. Umamaheswara Rao GS, Gallart L, Law-Koune JD, Lu Q, Puybasset L, Cluzel P, Coriat P, Rouby JJ. Factors influencing the tracheal fluctation of inhaled nitric oxide in patients with acute lung injury. Anesthesiology 1997;87:823-834.

35. Dambrosio M, Roupie E, Mollet JJ, Anglade MC, Vasile N, Lemaire F,
Brochard L. Effects of positive end-expiratory pressure and different tidal volumes on alveolar recruitment and hyperinflation. Anesthesiology 1997;87:495-503.

36. Malbouisson LM, Muller JC, Constantin JM, Lu Q, Puybasset L, Rouby JJ, and the CT Scan ARDS Study Group. Computed tomography assessment of positive end-expiratory pressure-induced alveolar recruitment in patients with acute respiratory distress syndrome. Am J Respir Crit Care Med 2001;163:1444-1450.

37. Brochard L. Watching what PEEP really does. Am J Respir Crit Care Med 2001;163:1291-1292.

38. Hayhurst MD, MacNee W, Flenley DC, Wright D, McLean A, Lamb D, Wightman AJ, Best J. Diagnosis of pulmonary emphysema by computerised tomography. Lancet 1984;11:320-322.

39. Brett SJ, Hansell DM, Evans TW. Clinical correlates in acute lung injury. Response to inhaled nitric oxide. Chest 1998;114:1397-1404.

40. Pelosi P, Goldner M, McKibben A, Adams A, Eccher G, Caironi P, Losappio S, Gattinoni L, Marini JJ. Recruitment and derecruitment during acute respiratory failure. An experimental study. Am J Respir Crit Care Med 2001;164:122-130.

41. Crotti S, Mascheroni D, Caironi P, Pelosi P, Ronzoni G, Mondino M, Marini JJ, Gattinoni L. Recruitment and derecruitment during acute respiratory failure-a clinical study. Am J Respir Crit Care Med 2001;164:131-140.

42. Hedenstierna G, Tokics L, Strandberg A, Lundquist H, Brismar B. Correlation of gas exchange impairment to development of atelectasis during anaesthesia and muscle paralysis. Acta Anaesthesiol Scand 1986; 30:183-191.

43. Slutsky AS, Scharf SM, Brown R, Ingram RH. The effect of oleic acidinduced pulmonary edema on pulmonary and chest wall mechanics in dogs. Am Rev Respir Dis 1980;121:91-96.

44. Gattinoni L, Pelosi P, Vitale G, Pesenti A, D'Andrea L, Mascheroni D. Body position changes redistribute lung computed-tomographic density in patients with acute respiratory failure. Anesthesiology 1991;74:15-23.

45. Gattinoni L, D'Andrea L, Pelosi P, Vitale G, Pesenti A, Fumagalli R. Regional effects and mechanism of positive end-expiratory pressure in early adult respiratory distress syndrome. JAMA 1993;269:2122-2127.

46. Pelosi P, D'Andrea L, Vitale G, Pesenti A, Gattinoni L. Vertical gradient of regional lung inflation in adult respiratory distress syndrome. Am J Respir Crit Care Med 1994;149:8-13.

47. Jones T, Jones HA, Rhodes CG, Buckingham PD, Hughes JMB. Distribution of extravascular fluid volumes in isolated perfused lungs measured with $\mathrm{H}_{2} \mathrm{O}$. J Clin Invest 1976;57:706-713.

48. Hales CA, Devid JK, Ahlualia B, Latty A, Erdman J, Javahery S, Kazeni H. Regional edema formation in isolated perfused dog lungs. Circ Res 1981;48:121-127.

49. Sandiford P, Province MA, Schuster DP. Distribution of regional density and vascular permeability in the adult respiratory distress syndrome. Am J Respir Crit Care Med 1995;151:737-742.

50. Redher K, Sessler AD, Rodarte JR. Regional intrapulmonary gas distribution in awake and anesthetized paralyzed man. J Appl Physiol 1977; 42:391-407.

51. Rosemblum LJ, Mauceri RA, Wellensteim DE, Thomas FD, Bassano DA, Raasch BN, Chamberlain CC, Heitzam ER. Density patterns in the normal lung as determined by computed tomography. Radiology 1980;137:409-416.

52. Agostoni E. Mechanics of pleural space. In: Maklem PT, Mead J, editors. Handbook of physiology. The respiratory system. Bethesda, MD: American Physiological Society; 1986, sect 3, III, p. 531-559.

53. Bone RC. The ARDS lung. New insights from computed tomography. JAMA 1993;269:2134-2135.

54. Albert RK, Hubmayr RD. The prone position eliminates compression of the lungs by the heart. Am J Respir Crit Care Med 2000;161:1660-1665.

55. Malbouisson LM, Busch CJ, Puybasset L, Lu Q, Cluzel P, Rouby JJ, and the CT Scan ARDS Study Group. Role of the heart in the loss of aeration characterizing lower lobes in acute respiratory distress syndrome. Am J Respir Crit Care Med 2000;161:2005-2012.

56. Wilson TA, Anafi RC, Hubmayr RD. Mechanics of edematous lungs. $J$ Appl Physiol 2001;90:2088-2093.

57. Martynowicz MA, Minor TA, Walters BJ, Hubmayr RD. Regional expansion of oleic acid-injured lungs. Am J Respir Crit Care Med 1999; 160:250-258.

58. Amato MB, Barbas CS, Medeiros DM, Magaldi RB, Schettino GP, Lorenzi-Filho G, Kairalla RA, Deheinzelin D, Munoz C, Oliveira R, et al. Effect of a protective-ventilation strategy on mortality in the acute respiratory distress syndrome. N Engl J Med 1998;338:347-354.

59. Suter PM, Fairley HB, Isemberg MD. Effect of tidal volume and positive end-expiratory pressure on compliance during mechanical ventilation. Chest 1978;73:158-162. 
60. Venegas JG, Harris RS, Simon BA. A comprehensive equation for the pulmonary pressure-volume curve. J Appl Physiol 1998;84:389-395.

61. Hickling KG. The pressure-volume curve is greatly modified by recruitment. A mathematical model of ARDS lungs. Am J Respir Crit Care Med 1998;158:194-202.

62. Jonson B, Richard JC, Straus C, Mancebo J, Lemaire F, Brochard L. Pressure-volume curves and compliance in acute lung injury. Am J Respir Crit Care Med 1999;159:1172-1178.

63. Richard JC, Maggiore SM, Jonson B, Mancebo J, Lemaire F, Brochard L. Influence of tidal volume on alveolar recruitment. Respective role of PEEP and a recruitment maneuver. Am J Respir Crit Care Med 2001; 163:1609-1613.

64. Gil J, Bachofen H, Gehr P, Weibel ER. Alveolar volume-surface area relation in air and saline-filled lungs by vascular perfusion. $J$ Appl Physiol 1979;47:990-1001.

65. Pelosi P, Cadringher P, Bottino N, Panigada M, Carrieri F, Riva E, Lissoni A, Gattinoni L. Sigh in acute respiratory distress syndrome. Am J Respir Crit Care Med 1999;159:872-880.

66. Greves IA, Hildebrandt J, Hoppin FJ. Micromechanics of the lung. In: Fishman AP, Macklem PT, Mead J, Geiger SR, editors. Handbook of physiology. The respiratory system. Bethesda, MD: American Physiological Society; 1986, sect 3, III, p. 217-231.

67. Rothen HU, Sporre B, Engberg G, Wegenius G, Hedenstierna G. Reexpansion of atelectasis during general anesthesia: a computed tomography study. Br J Anaesth 1993;71:788-795.

68. Gattinoni L, Pelosi P, Crotti S, Valenza F. Effects of positive end-expiratory pressure on regional distribution of tidal volume and recruitment in adult respiratory distress syndrome. Am J Respir Crit Care Med 1995; 151:1807-1814.

69. Muscedere JG, Mullen JBM, Gan K, Slutsky AS. Tidal ventilation at low airway pressures can augment lung injury. Am J Respir Crit Care Med 1994;149:1327-1334.

70. Trembley L, Valenza F, Ribeiro SP, Li J, Slutsky AS. Injurious ventilatory strategies increase cytokines and c-fos m-RNA expression in an isolated rat lung model. J Clin Invest 1997;99:944-952.
71. Chiumello D, Prostine G, Slutsky AS. Mechanical ventilation affects local and systemic cytokines in an animal model of acute respiratory distress syndrome. Am J Respir Crit Care Med 1999;160:109-116.

72. Ranieri VM, Suter PM, Tortorella C, De Tullio R, Dayer JM, Brienza A Bruno F, Slutsky AS. Effect of mechanical ventilation on inflammatory mediators in patients with acute respiratory distress syndrome: a randomized controlled trial. JAMA 1999;282:54-61.

73. Tagliabue M, Casella TC, Zincone GE, Fumagalli R, Salvini E. CT and chest radiography in the evaluation of adult respiratory distress syndrome. Acta Radiol 1994;35:230-234.

74. Desai SR, Hansell DM. Lung imaging in the adult respiratory distress syndrome: current practice and new insights. Intensive Care Med 1997; 93:7-15.

75. Markstaller K, Kauczor HU, Eberle B, Weiler N, Siebertz D, Birkenkamp K, Heinrichs W, Thelen M. Multi-rotation CT during continuous ventilation: comparison of different density areas in healthy lungs and in the ARDS lavage model. Rofo Fortschr Geb Rontgenstr Neuen Bildgeb Verfahr 1999;170:575-580.

76. Recheis W, Kleinsasser A, Hatschenberger R, Knapp R, Hoermann C, zur Nedden D. Respirator triggering of electron beam computed tomography (EBCT): research on vital capacities. Coll Antropol 1999; 23:473-482.

77. Schuster DP. The evaluation of lung function with PET. Semin Nucl Med 1998;28:341-351.

78. Uematsu H, Levin DL, Hatabu H. Quantification of pulmonary perfusion with MR imaging: recent advances. Eur J Radiol 2001;37:155-163.

79. Schoepf UJ, Bruening R, Konschitzky H, Christoph RB, Knez A, Weber J, Muehling O, Herzog P, Huber A, Haberl R, et al. Pulmonary embolism: comprehensive diagnosis by using electron-beam CT for detection of emboli and assessment of pulmonary blood flow. Radiology 2000; 217:693-700.

80. Hoffman E, Tajik JK, Kugelmass SD. Matching pulmonary structure and perfusion via combined dynamic multislice CT and thin-slice high-resolution CT. Comput Med Imaging Graph 1995;19:101-112. 